\title{
Capitalismo, agricultura familiar e mercantilização ${ }^{12}$
}

Capitalism, family farming and commodification

Clério Plein ${ }^{3}$

\begin{abstract}
Resumo: O objetivo do texto é fazer uma revisão das principais abordagens sobre agricultura familiar e buscar uma síntese a partir da noção de mercantilização para compreender as particularidades dessa forma social de produção, baseada na mão-de-obra familiar, no interior do modo capitalista de produção. Trata-se de um ensaio teórico e como principal conclusão destaca-se o fato de que compreender a estrutura e a dinâmica dos mercados acessados pelos agricultores familiares pode ser uma pista importante para analisar a sua reprodução social.
\end{abstract}

Palavras-chave: Teoria Social, Agricultura Familiar, Mercantilização, Mercados.

\begin{abstract}
The objective of this paper is to review the main approaches in family farming and get a summary from the notion of commodification to understand the particularities of this social form of production, based on manpower family, within the capitalist mode of production. This is a theoretical essay and a principal conclusion we highlight the fact that understanding the structure and dynamics of markets accessed by farmers can be an important clue to analyze its social reproduction.
\end{abstract}

Key Words: Social Theory, Family Farming, Commodification, Markets.

J EL: P1; Q13; Z1.

\section{Introdução}

No Brasil, de acordo com os dados preliminares do Censo Agropecuário de 2006, a agricultura familiar ${ }^{4}$ está presente em 84,4\% dos estabelecimentos, ocupa 24,3\% da área total, é responsável por 38\% do Valor Bruto da Produção, ocupa 74,4\% das pessoas. A agricultura familiar é responsável pela produção de $87 \%$ da mandioca, $70 \%$ do feijão, $46 \%$ do milho, 38\% do café, 34\% do arroz, $21 \%$ do trigo, $16 \%$ da soja, $58 \%$ do leite, 50\% das aves, 59\% dos suínos e 39\% dos bovinos (BRASIL, 2009; IBGE, 2009). Esses dados demonstram uma questão que nem sempre foi tão clara assim. Historicamente, existiam muitas dúvidas sobre os atributos sócio-econômicos da agricultura familiar enquanto "modelo" de desenvolvimento, sobretudo, considerando qual seria o seu comportamento e seu futuro com a evolução e consolidação do modo capitalista de produção.

O debate sobre a agricultura familiar no capitalismo não é um tema novo. Na literatura, as discussões se voltam para a permanência, ou não, dessa forma de produção, com o desenvolvimento das relações capitalistas no campo. Outros procuram entender o seu modo de funcionamento, bem como a sua integração no

\footnotetext{
${ }^{1}$ Artigo recebido em agosto de 2010 e aprovado em dezembro de 2010.

2 A elaboração desse texto tem um débito com dois grandes mestres, Zander Navarro e Sergio Schneider, cabendo as isenções de praxe.

3 Doutorando e Mestre em Desenvolvimento Rural (PGDR/UFRGS), graduado em Economia Doméstica pela Universidade Estadual do Oeste do Paraná (UNIOESTE), professor e pesquisador da UNIOESTE/ Campus Francisco Beltrão, Paraná. E-mail: clerioplein@ig.com.br.

${ }^{4}$ A agricultura familiar foi definida com base na Lei 11.326 de 24 de julho de 2006 que estabelece os seguintes critérios: a área do estabelecimento ou empreendimento rural não excede quatro módulos fiscais; a mão-de-obra utilizada nas atividades econômicas é predominantemente da própria família; a renda familiar é predominantemente originada das atividades vinculadas ao próprio estabelecimento; o estabelecimento ou empreendimento é dirigido pela família (BRASIL, 2009).
} 
sistema social e econômico dominante. Embora seja uma temática recente nos estudos acadêmicos sobre o mundo rural, o que diferencia as abordagens da agricultura familiar, são as ferramentas utilizadas para sua análise. De modo geral, pode-se destacar três grandes vertentes (ou fontes de inspiração) dos estudos sobre agricultura familiar: o marxismo, o chayanoviano e o weberiano.

A primeira vertente possui sua base epistemológica baseada em Marx e seus seguidores, sobretudo Lênin e Kaustky. A preocupação central é com o desenvolvimento do capitalismo na agricultura. Os dois conceitos basilares são a divisão social do trabalho e a apropriação privada do valor. Trata-se de uma abordagem macro (econômica, social e política) ${ }^{5}$. A segunda vertente é inspirada na obra de Chayanov. Trata-se de uma abordagem que inverte o enfoque da anterior, pois sua ênfase é microeconômica. Não desconhece o ambiente macro (capitalismo), entretanto, considera que o indivíduo é capaz de reagir ao sistema, adotando diferentes estratégias de reprodução ${ }^{6}$. Já a terceira vertente é influenciada por Weber, que não se preocupou em fazer uma teoria de explicação da sociedade, mas sim, em criar um modelo de análise para as situações. Ênfase no modelo de funcionamento da agricultura e utilização de "tipos ideais" para a análise7.

Diante desse contexto, o objetivo deste ensaio teórico é fazer uma revisão das principais abordagens sobre a agricultura familiar e buscar uma síntese a partir da noção de mercantilização para compreender as particularidades da reprodução dessa forma social de produção com base na mão-de-obra familiar no capitalismo. Para tanto, o trabalho, além da introdução e das considerações finais está estruturado em três partes. Na primeira são retomadas algumas contribuições consideradas clássicas de autores marxistas e neomarxistas, de enfoque econômico e estrutural. Se os primeiros demonstraram que não haveria lugar para os agricultores familiares no capitalismo, os segundos tentaram entender porque os mesmos persistem apesar do avança das relações capitalistas de produção. Na segunda parte são apresentadas algumas interpretações consideradas alternativas ao marxismo, com um enfoque antropológico e sociológico, eu seja, consideram os indivíduos, os atores. São contribuições que tentam demonstrar que existe lugar para os agricultores familiares no sistema capitalista. Na terceira parte, com base em autores que buscam uma síntese das abordagens anteriores, são apresentados elementos que demonstram as transformações por que passaram os agricultores em função da sua maior inserção nos mercados, ampliando o processo de mercantilização da agricultura familiar.

\section{As Interpretações Clássicas sobre Agricultura Familiar no Marxismo e a Revisão de Autores Neomarxistas}

No que se refere ao desenvolvimento agrário, considera-se que a tradição marxista traz contribuições universais e conjunturais, entretanto, sobre o mundo rural é limitada e parcial, uma vez que Marx não se interessou diretamente pelo mundo rural, que era considerado "o passado" do sistema capitalista. É possível sintetizar a contribuição de Marx sobre o mundo rural em três grandes blocos: a) $\mathrm{O}$ capital, sobretudo o Livro I (acumulação de capital) e Livro III (Renda da terra), o

\footnotetext{
${ }^{5}$ Como exemplos, pode-se citar os trabalhos de Germer (1999), Moreira (1999) e Graziano da Silva (1999).

6 Um exemplo dessa abordagem é o trabalho de Garcia Jr (1989) e Heredia (1979).

${ }^{7}$ Um exemplo de utilização deste referencial pode ser encontrado em Lamarche (1993 e 1999).
} 
que representa uma interpretação econômica e tecnológica: b) O 18 de Brumário, que corresponde a uma interpretação política e conjuntural; c) Marx e os populistas russos $^{8}$, que demonstra a incerteza de Marx em relação à Rússia e ao lugar da agricultura familiar. Entretanto, a tradição marxista está atrelada basicamente aos dois primeiros blocos, que dão ênfase ao desaparecimento dos camponeses com o desenvolvimento do capitalismo ${ }^{9}$, porém, é no seu diálogo com os populistas russos que Marx coloca uma questão fundamental para compreender o desenvolvimento da agricultura familiar, qual seja, "as particularidades históricas", uma vez que aquilo que Marx observou na Inglaterra e na França, não é, necessariamente, válido para compreender a agricultura familiar em todos os contextos.

As teses marxistas clássicas apontavam para o desaparecimento da agricultura familiar com o desenvolvimento das relações capitalistas na agricultura, sobretudo nas obras de Kautsky e Lênin. Kautsky apontava para a superioridade técnica do grande estabelecimento, afirmando que "quanto mais a agricultura se identifica com os padrões capitalistas, tanto mais se diferenciam qualitativamente as diferenças técnicas empregadas pelos grandes estabelecimentos das empregadas pelos pequenos" (KAUSTKY, 1986, p. 87). Lênin falava da ruína, desintegração e diferenciação camponesa, dizendo que "o processo de decomposição dos pequenos agricultores em patrões e operários agrícolas constitui a base sobre a qual se forma o mercado interno na produção capitalista" (LENIN, 1985, p. 35).

Entretanto, constatou-se o predomínio da agricultura familiar na estrutura agrária nos países onde o modo de produção capitalista mais se desenvolveu, sobretudo no período pós-guerra (1945-1973), fase denominada por Hobsbawm (1995), de os "anos dourados" da era de ouro do capitalismo ${ }^{10}$. De acordo com Veiga (1991, p. 188), "durante o grande impulso do desenvolvimento capitalista (meados da década de 1930 ao início da década de 1970) foi a agricultura familiar que acabou se firmando em todos os países do chamado Primeiro Mundo". Para Abramovay (1992, p. 19), "é fundamentalmente sobre a base de unidades familiares de produção que se

\footnotetext{
${ }^{8}$ Veja-se o livro organizado por Fernandes (1982). Trata-se de uma coletânea de cartas trocadas entre Marx e os Populistas Russos. Os Populistas Russos indagam Marx sobre o futuro da comuna rural. Marx mostra-se indeciso na resposta à Vera Zasulitch: escreve o primeiro rascunho (11 páginas) da resposta em fevereiro - março de 1881, mas não a envia. Posteriormente, (08 de março de 1881) reescreve a carta (somente 2 páginas), porém não envia novamente. Na carta, percebe-se que Marx está claramente indeciso em relação à comuna, bem como, chama atenção para o fato de que talvez não tenham compreendido sua teoria corretamente, e ainda, a necessidade de considerar as particularidades de cada lugar, conforme pode ser observado nas passagens abaixo: "(...) Mas espero que algumas linhas sejam suficientes para não lhe deixar qualquer dúvida sobre o mal-entendido a respeito de minha suposta teoria (...) No fulcro do sistema capitalista está, portanto, a separação radical entre o produtor e os meios de produção (...) A base de toda essa evolução é a expropriação dos cultivadores. Até agora, só na Inglaterra ela se completou de modo radical (...) Mas todos os países da Europa Ocidental percorrem o mesmo movimento (...) portanto, a "fatalidade histórica" desse movimento está expressamente restringida aos países da Europa Ocidental (...) A propriedade privada, fundada sobre o trabalho pessoal (...) será suplantada pela propriedade privada capitalista, fundada sobre a exploração do trabalho alheio, sobre o trabalho assalariado (...) Nesse movimento ocidental trata-se, portanto, da transformação de uma forma de propriedade privada em outra forma de propriedade privada. Entre os camponeses russos, tratar-se-ia, ao contrário, de transformar sua propriedade comum em propriedade privada. A análise feita em $\mathrm{O}$ capital não confere, portanto, razões nem a favor nem contra a vitalidade da comuna rural (...)".

${ }^{9}$ Veja-se o texto de Mitrany (1957).

10 Apesar deste autor, de inspiração marxista, ter decretado o fim do campesinato, conforme pode ser visto nessa passagem: "A mudança social mais impressionante e de mais longo alcance da segunda metade deste século, e que nos isola para sempre do mundo do passado, é a morte do campesinato" (HOBSBAWM, 1995, p. 284).
} 
constitui a imensa prosperidade que marca a produção de alimentos e fibras nas nações mais desenvolvidas”. Nas palavras de J ean (1994):

\begin{abstract}
Há mais de um século, o futuro da agricultura familiar tem sido alvo de um número impressionante de especulações as mais diversas. Se muitos tomavam sua defesa, mais de um profetizava seu desaparecimento próximo, ilustrava seu processo de decomposição para dar lugar a uma forma superior ou mais evoluída de exploração agrícola, seja a fazenda capitalista para uns ou a fazenda coletiva para outros. De todos os lados tentaram nos fazer crer que sua tarefa histórica se acabava (...). Por outro lado, a produção familiar agrícola parece ter sido capaz de gerar uma curiosa capacidade de manter-se, de reproduzir-se ao longo das gerações, de adaptar-se aos movimentos da conjuntura sócio-econômica e isto, independentemente dos regimes políticos, tão diferentes de norte a sul, de leste a oeste, nos quais ela foi levada a evoluir (J ean, 1994, p. 51).
\end{abstract}

Diante desse quadro, portanto, o debate passou a concentrar-se em torno da persistência, no capitalismo, das unidades agrícolas baseadas no trabalho familiar. Grosso modo, pode-se considerar como características básicas do modo de produção capitalista: i) as relações de produção se baseiam na propriedade privada dos meios de produção; ii) trata-se de uma sociedade de classes, ou seja, capitalistas (donos dos meios de produção) e assalariados (que vendem sua força de trabalho aos primeiros); iii) acumulação de capital com extração de mais-valia, sendo que o objetivo é a produção de mercadorias que proporcionem lucro. Porém, o camponês ou agricultor familiar era visto como "anacrônico" dentro deste sistema, pois: i) é, ao mesmo tempo, administrador, proprietário dos meios de produção e força de trabalho; ii) a produção é tanto voltada para o auto-abastecimento como para a geração de excedente. Metaforicamente, o agricultor familiar era considerado uma espécie de "ornitorrinco" dentro do sistema capitalista. Ou como afirma Jean (1994), "o agricultor moderno apresenta-se então como um personagem híbrido acumulando nele mesmo uma tríplice identidade: proprietário fundiário, empresário privado e trabalhador" (p. 53).

Para Schneider (2003), o debate marxista sobre a agricultura familiar e as relações sociais por ele engendradas permaneceu circunscrita ao seu papel econômico no interior do processo de desenvolvimento do capitalismo. O desafio era investigar se a instauração do modo de produção capitalista acarretava ou não determinadas formas de propriedade e um certo tipo de estrutura de classes. O novo desafio ${ }^{11}$ que estava lançado para o materialismo histórico era sua capacidade ou não, de explicar a persistência da agricultura familiar. A resposta foi positiva, entretanto, os autores refutaram três idéias da teoria marxista: i) a teoria da renda da terra de Marx; ii) a teoria da diferenciação social de Lênin; iii) a idéia e/ ou conceito de camponês como categoria política.

As teses neomarxistas, destacadas por Schneider (2003), dão conta de que a permanência da agricultura familiar no capitalismo se deve a duas razões: i) os obstáculos naturais ao desenvolvimento do capitalismo na agricultura (Susan Mann e David Goodman); ii) as especificidades da agricultura familiar e a produção simples de mercadorias (Claude Servolin e Harriet Friedmann). Na revisão, Schneider (2003) apresenta a seguinte argumentação: 1) De acordo com Susan Mann (MANN;

\footnotetext{
${ }^{11}$ De acordo com J ean (1994, p. 52) "será necessário explicarmos porque esta agricultura, longe de ser uma forma social de organização da produção agrícola em perigo, não sendo, portanto, um anacronismo histórico, é um produto do próprio desenvolvimento da economia agrícola moderna".
} 
DIKCINSON, 1987), em comparação com a indústria, na agricultura existe uma diferença entre tempo de trabalho e tempo de produção, bem como, o problema da perecibilidade dos produtos agrícolas. Como resultado destas caracteísticas naturais, as atividades agrícolas se tornam um empreendimento de alto risco para o capital que pode optar por atividades industriais para obter mais lucro; 2) Na concepção de David Goodmann (GOODMAN, SORJ e WILKINSON, 1990), existe a incapacidade de converter a agricultura num ramo da indústria, ocorrendo apenas, o apropricionismo (apropriação de elementos da produção agrícola, sua transformação em atividades agrícolas e sua reincorporação como insumos) e o substitucionismo (substituição dos alimentos agrícolas por produtos industrializados). A indústria não se apropria do processo produtivo agrícola, mas se torna fornecedora de equipamentos e insumos e processa a matéria-prima; 3) Para Claude Servolin (SERVOLIN, 1972), ocorre a produção mercantil simples articulada com o modo de produção capitalista através da troca de mercadorias entre pequenos agricultores e as agroindústrias. A agricultura familiar significaria, portanto, uma forma interessante para o capital (urbano-industrial), possibilitando alimentos a preços baixos para a classe trabalhadora, o que representaria vantagens comparativas em relação à produção capitalista; 4) De acordo com Harriet Friedmann (FRIEDMANN, 1972) nas unidades familiares (produção mercantil simples) os proprietários da força de trabalho e dos meios de produção encontram-se reunidos em uma única unidade e possuem relações de parentesco entre si, já na produção mercantil capitalista implica na obtenção de mais-valia (acumulação de capital). Portanto, a produção mercantil simples busca atender, prioritariamente, aos interesses de reprodução do núcleo familiar.

Portanto, para Schneider (2003), de acordo com os autores neomarxistas, o que explica e permanência da agricultura familiar no capitalismo são os obstáculos naturais e a forma de organização do trabalho e da produção. Ao contrário das teses clássicas do marxismo, a agricultura familiar seria uma forma interessante para a acumulação de capital, uma vez que: i) o capitalismo só se sustenta pela acumulação de capital; ii) a agricultura familiar não visa taxa de lucro, mas a remuneração da mão-de-obra familiar, conseguindo, portanto, produzir alimentos mais baratos; iii) o preço do alimento é fator essencial para o capitalista, do ponto de vista da reprodução da força de trabalho.

Desta breve síntese do debate sobre o lugar da agricultura familiar no interior do desenvolvimento capitalista, feita por autores marxistas e neomarxistas, destacase alguns elementos importantes para o objetivo desse ensaio: a) é preciso pensar a agricultura familiar dentro do sistema capitalista - que até hoje não mostrou sinais de "ruína", muito pelo contrário, tem demonstrado uma incrível capacidade de adaptação; b) se o modo de produção é capitalista, focar o entendimento dos mercados ${ }^{12}$ pode ser um recurso analítico interessante para compreender a reprodução social da agricultura familiar, bem como, as transformações que sofre; c) as concepções marxistas clássicas de que não haveria lugar para a agricultura familiar mostraram-se equivocadas, entretanto, foi o próprio Marx que alertou para as "particularidades", questão esquecida por muitos de seus seguidores; d) a contribuição dos autores neomarxistas trás elementos significativos para a análise, ou seja, permanece a ênfase nas condições materiais em que ocorre a reprodução social

\footnotetext{
12 Não estamos assumindo aqui a ideia de que o mercado é sinônimo de capitalismo (questão que está na raiz do debate entre os defensores do conceito de campesinato $\mathrm{x}$ agricultura familiar), mas pelo contrário, partilhamos da ideia de Polanyi (1976) de que os mercados são anteriores ao capitalismo, uma vez que sempre existiram trocas, mais ou menos monetizadas.
} 
da agricultura familiar, porém, considerando os obstáculos naturais e as vantagens da mão de obra familiar para o desenvolvimento da sociedade capitalista.

\title{
3 Invertendo o Foco: Algumas Interpretações Alternativas ao Marxismo
}

Para Marx, Lenin e Kautsky, em função da lógica de expansão do capitalismo na agricultura, as formas não capitalistas como a agricultura familiar seriam, inevitavelmente, eliminadas. A perspectiva de Chayanov (1974) se contrapõe a essa abordagem. Ao invés de considerar a lógica capitalista (macro), formula uma perspectiva analítica que parte da lógica da família do agricultor (micro), ou seja, estuda a morfologia da unidade econômica camponesa, argumentando que os agricultores possuem uma racionalidade própria (fortemente baseada na relação trabalho e consumo), estabelecendo estratégias de reprodução. Portanto, os agricultores não são simplesmente "vítimas" das leis do capitalismo, pelo contrário, eles reagem ao processo e buscam alternativas.

Outro autor que apresenta elementos importantes para compreender os camponeses é Mendras. De acordo com Mendras (1978), "uma sociedade camponesa é um conjunto relativamente autônomo no seio de uma sociedade global mais larga". O autor, aponta cinco traços básicos do que seria um tipo ideal de sociedade camponesa, estes traços são relacionados entre si e formam um modelo geral.

\begin{abstract}
1. A autonomia relativa das coletividades camponesas frente a uma sociedade envolvente que as domina mas tolera as suas originalidades. 2. A importância estrutural do grupo doméstico na organização da vida econômica e da vida social da coletividade. 3. Um sistema econômico de autarcia relativa e que tem relações com a economia envolvente. 4. Uma coletividade local caracterizada por relações internas de interconhecimento e de relações débeis com as coletividades circunvizinhas. 5. A função decisiva do papel dos notáveis entre as coletividades camponesas e a sociedade envolvente (Mendras, 1978, p. 14-5).
\end{abstract}

Entretanto, uma das características que distingue o campesinato europeu do campesinato americano, já apontada por Weber (1974), é que na América, o mercado foi anterior ao campesinato, ou seja, aqui, o agricultor sempre produziu para o mercado.

Êle é totalmente diferente do agricultor da Inglaterra ou da América. O primeiro é hoje, por vêzes, um empresário e produtor notável para o mercado; quase sempre, alugou a sua propriedade. O fazendeiro americano é um agricultor que habitualmente adquiriu, pela compra ou por ser o primeiro colonizador, a terra como sua propriedade pessoal; mas pôr vêzes a aluga. Na América, o agricultor produz para o mercado. 0 mercado é mais antigo do que êle na América. O camponês europeu do tipo antigo era um homem que, na maioria dos casos, herdou a terra e produzia principalmente para atender às suas próprias necessidades. Na Europa, o mercado é mais nôvo do que o produtor. É claro que durante muitos anos o camponês vendeu seus excedentes e, embora tecesse e fiasse, não podia satisfazer suas necessidades com o seu próprio trabalho. Os últimos dois mil anos não treinaram o camponês para produzir visando ao lucro (WEBER, 1974, p. 415). Grifo nosso. 
Porém, essa relação dos colonos com o mercado possuía algumas particularidades. Nesse sentido, uma contribuição para entender esse processo é a de Ellis (1988), que considera que os camponeses se caracterizam pela sua inserção parcial em mercados incompletos. Para a autora, existem cinco aspectos que caracterizam a parcialidade e a imperfeição desses mercados. Em primeiro lugar, os mercados de capitais e crédito, são fragmentários ou inexistentes, sendo que o crédito é obtido de fontes locais e está ligado a condições pessoais de dominação dos proprietários de terras e/ ou dos comerciantes sobre os camponeses. Segundo, não é num quadro competitivo que os camponeses têm acesso a insumos de origem industrial necessários a sua produção. Terceiro, as informações sobre a situação de mercado são pobres e erráticas, reforçando a dependência entre o camponês e os comerciantes locais. Além disso, os critérios de ocupação e transferência de terras submete-se a regras estabelecidas no âmbito da comunidade local. Finalmente, as dificuldades de transporte e comunicação, reforçam o poder dos comerciantes locais sobre os camponeses.

Invertendo a ótica da análise, percebe-se, com base nesses autores, que a agricultura familiar possui lógicas próprias, entretanto, á medida que estabelece relações com os mercados, essa lógica vai sofrendo transformações, conforme o próprio Chayanov já chamava atenção. Chayanov (1974), aponta para a transformação da economia camponesa quando é amplamente baseada nas transações mercantis:

As atividades na unidade de exploração adquirem um caráter totalmente
distinto quando esta ingressa na esfera da circulação de dinheiro e
mercadorias. A atividade econômica perde sua matriz qualitativa. Agora as
demandas podem satisfazer-se mediante compras; o interesse pela
"quantidade" - obtenção da maior quantidade que, ao ser intercambiada,
pode tomar qualquer forma "qualitativa" necessária para cobrir as
necessidades familiares - passa agora a frente. Ao desenvolver sua natureza
monetária, a "quantidade" obtida vai se liberando cada vez mais da
"qualidade" e começa a adquirir o caráter abstrato de "valor". [...] ao
desenvolver-se a natureza produtora de mercadorias na unidade de
exploração, a organização desta em um sistema monetário, totalmente
estabelecido pelas necessidades de consumo da família começa a receber
cada vez mais a influência da situação do mercado no que diz respeito a
composição da unidade, e as necessidades de consumo somente continuaram
pressionando para determinar o volume total da atividade (Chayanov, 1974,
p. 140-1). Tradução livre. Grifos nossos.

De acordo com Chayanoy (1974), para que a agricultura ingresse no sistema capitalista mais geral não é necessária a criação de unidades de produção muito grandes, organizadas ao modo capitalista sobre a base da força de trabalho assalariada. Pois, a agricultura saindo de uma existência semi-natural, se submete ao capitalismo comercial que, muitas vezes, está sob a forma de empresas comerciais em grande escala, que conduzem massas dispersas de unidades econômicas camponesas à sua esfera de influência e vinculam com o mercado estes produtores de mercadorias em pequena escala, para subordiná-los economicamente. De acordo com Chayanov,

Estes vínculos comerciais que convertem a exploração familiar natural isolada em uma pequena produtora de mercadorias são sempre as primeiras maneiras de organizar as unidades econômicas camponesas dispersas e de abrir as primeiras vias de penetração às relações capitalistas no campo. Mediante estas conexões, cada pequena empresa camponesa se converte em 
uma parte orgânica da economia mundial, experimenta em si mesma os efeitos da vida econômica geral do mundo, é poderosamente dirigida em sua organização pelas demandas econômicas do mundo capitalista e, por sua vez, junto com milhões semelhantes a ela, afeta todo o sistema da economia mundial (Chayanov, 1974, p. 306). Tradução livre. Grifos nossos.

Qual o aprendizado com esses autores? a) a análise da agricultura familiar precisa considerar, além dos processos mais gerais que dizem respeito às lógicas do capitalismo, as lógicas das famílias camponesas, como destacam Chayanov, Mendras e Ellis; b) essas lógicas possuem outra racionalidade, entretanto, vai sofrendo influências externas à medida que estabelece relações mercantis; c) a contribuição de Weber é central ao apontar que a existência do mercado como sendo anterior ao campesinato na América, o que reforça nossa tentativa de compreender a reprodução social da agricultura familiar via mercados; d) através da relação com os mercados a reprodução social da agricultura familiar passa a sofrer influências externas, é o que veremos agora.

\section{Agricultura Familiar no Brasil, Metamorfoses e Mercantilização ${ }^{13}$ : em busca de uma síntese!?}

No Brasil, o debate sobre a agricultura familiar ganha força a partir do final dos anos 1980 e início dos anos 1990, sendo que a emergência da expressão "agricultura familiar" parece ocorrer, simultaneamente, nas esferas política e acadêmica (Plein, 2003). No cenário político, os movimentos sociais ligados à agricultura familiar, ganham maior espaço com o processo de abertura comercial e econômica iniciado pelo governo Collor. Esses movimentos procuram discutir sobre o espaço e o papel dos pequenos produtores rurais, principalmente da região Sul do Brasil, no processo de integração comercial e econômica dos países que formam o Mercosul. A legitimação, perante o Estado, ocorre em meados dos anos 1990, especialmente com os dados do FAO/INCRA (1996) ${ }^{14}$, elaborados a partir do Censo Agropecuário de 1995/ 96 e a criação de uma política específica para este segmento da agricultura brasileira, o PRONAF - Programa Nacional de Fortalecimento da Agricultura Familiar (Plein; Schneider, 2003). Segundo Schneider (1999), no ambiente acadêmico, os trabalhos de Veiga (1991), Abramovay (1992) e Lamarche (1993, 1999), "mostraram que a agricultura familiar é uma forma social reconhecida e legitimada na maioria dos países desenvolvidos", reconhecendo a importância dessa temática.

Apesar da noção "agricultura familiar" ser recente no Brasil, as categorias sociais que ela pretende identificar não são novas. De acordo com Porto e Siqueira (1994), no período de 1950 a 1970, falava-se em campesinato, que era um conceito

13 O termo mercantilização é utilizado para representar o processo de integração da agricultura familiar aos mercados, como por exemplo, na comercialização da produção, aquisição de insumos e acesso ao crédito.

${ }^{14}$ Esses dados revelaram que no Brasil, 85,2\% dos estabelecimentos eram familiares, ocupando 30,5\% da área, responsáveis por $37,9 \%$ do VBP e que recebiam somente $25,3 \%$ dos financiamentos. Importante lembrar que a definição de agricultura familiar do FAO/ INCRA é diferente da definição adotada pelo PRONAF. No estudo FAO/INCRA, "o universo familiar foi caracterizado pelos estabelecimentos que atendiam, simultaneamente, às seguintes condições: a) a direção dos trabalhos do estabelecimento era exercida pelo produtor; b) o trabalho familiar era superior ao trabalho contratado (Projeto de Cooperação Técnica INCRA/ FAO, 2000). 
carregado de conteúdo político e ideológico. A partir de 1970, a discussão centrava-se em torno do conceito de pequena produção ou produtores de baixa renda, tendo em vista as transformações políticas do Estado brasileiro e o processo conhecido como "modernização conservadora" 15 . Havia ainda a discussão em torno da funcionalidade da agricultura para o desenvolvimento urbano-industrial do país. ${ }^{16} \mathrm{Já}$ a partir dos anos 1980, o debate sobre a pequena produção ganha uma certa classificação, entre integrados, excluídos e subsistência. Entre os excluídos, a discussão centra-se em torno dos sem-terra, parceiros, meeiros, trabalhadores temporários, posseiros, agregados e moradores. Nos anos 1990, o estudo da FAO/INCRA (1996), também classifica os agricultores familiares entre consolidados, em transição e periféricos, de acordo com as suas rendas. Atualmente, não existe um consenso em relação á definição de agricultura familiar, entretanto, a argumentação de Abramovay (1997) parece bastante apropriada, destacando alguns aspectos relevantes.

\begin{abstract}
A agricultura familiar é aquela em que a gestão, a propriedade e a maior parte do trabalho vêm de indivíduos que mantêm entre si laços de sangue ou de parentesco. Que esta definição não seja unânime e muitas vezes tampouco operacional é perfeitamente compreensível, já que os diferentes setores sociais e suas representações constroem categorias científicas que servirão a certas finalidades práticas: a definição de agricultura familiar, para fins de crédito, pode não ser exatamente a mesma daquela estabelecida com finalidades de quantificação estatística num estudo acadêmico. O importante é que estes três atributos básicos (gestão, propriedade e trabalho familiares) estão presentes em todas elas (Abramovay, 1997, p. 03).
\end{abstract}

Como o estudo da agricultura familiar é uma discussão recente no Brasil, uma contribuição original foi a de Abramovay (1992), que seguindo autores como Redfield, Shanin, Ellis, Mendras, entre outros, foi o primeiro no Brasil a distinguir o campesinato, também denominado de sociedades camponesas, da agricultura familiar. O autor demonstrou que a agricultura familiar é oriunda do campesinato, no entanto, ela representa uma forma de organização do trabalho e da produção bastante distinta, em função da sua crescente integração aos mercados. Isso não significa que a agricultura familiar seja algo inteiramente distinto, ou completamente diferente. Ao contrário, a agricultura familiar tem as suas origens históricas no campesinato, só que ela é uma superação das formas camponesas, pois, a rigor, este representa um modo de vida. E quanto mais esse modo de vida vai sendo transformado pela sua interação, cada vez maior, com a sociedade capitalista, isso vai levar, ao mesmo tempo, ao desaparecimento desse modo de vida e ao surgimento de uma agricultura familiar "mercantilizada". De acordo com Abramovay (1992):

As sociedades camponesas são incompatíveis com o ambiente econômico onde imperam relações claramente mercantis. Tão logo os mecanismos de preços adquiram a função de arbitrar decisões referentes à produção, de funcionar como princípio alocativo do trabalho social, a reciprocidade e a personalização dos laços sociais perderão inteiramente o lugar, levando consigo o próprio caráter camponês da organização social (p. 117).

\footnotetext{
${ }^{15}$ A denominação de modernização conservadora se deve ao fato de que alterou-se a base técnica da produção, porém, sem mexer na estrutura fundiária do país (Graziano da Silva, 1982).

${ }_{16}$ Oliveira (1988), destaca que a agricultura teve um papel central no processo de acumulação urbanoindustrial do país. Por um lado, fornecendo o "exército industrial de reserva", e por outro, produzindo alimentos baratos, rebaixava o custo de reprodução da força de trabalho urbana, assim, possibilitava a manutenção de baixos salários, e conseqüentemente, uma maior acumulação de capital.
} 
Nesse sentido, o que parece ter contribuído para a "ruptura" entre a agricultura camponesa e a agricultura familiar foi a crescente mercantilização. Essa crescente integração ao mercado, acabou levando as decisões "para fora da porteira", aumentando a integração dos agricultores à sociedade capitalista. Abramovay (1992) referindo-se ao caso dos camponeses do sul do Brasil, afirma que estes:

\begin{abstract}
(...) integram-se plenamente a estas estruturas nacionais de mercado, transformando não só sua base técnica, mas sobretudo o círculo em que se reproduzem e metamorfoseiam-se numa nova categoria social. De camponeses, tornam-se agricultores profissionais. Aquilo que antes era um modo de vida converte-se numa profissão, numa forma de trabalho. $\mathrm{O}$ mercado adquire a fisionomia impessoal com que se apresenta aos produtores numa sociedade capitalista. Os laços comunitários perdem seu atributo de condição básica para a reprodução material. Os códigos sociais partilhados não possuem mais as determinações locais, por onde a conduta dos indivíduos se pautava pelas relações de pessoa a pessoa. Da mesma forma, a inserção do agricultor na divisão do trabalho corresponde à maneira universal como os indivíduos se socializam na sociedade burguesa: a competição e a eficiência convertem-se em normas e condições da reprodução social (p. 126-7). Grifos no original.
\end{abstract}

De acordo com Ploeg (1992), o processo de trabalho agrícola, através da crescente mercantilização, torna a reprodução, que era autônoma (agricultura camponesa), cada vez mais externalizada e dependente do mercado (agricultura familiar), conforme Figura 01.

Figura 01 - Reprodução autônoma (agricultura camponesa) x reprodução dependente do mercado (agricultura familiar) nas esferas da produção e circulação

\begin{tabular}{|c|c|c|c|c|c|}
\hline Esfera & \multicolumn{3}{|c|}{$\begin{array}{l}\text { Esquema de reprodução relativamente } \\
\text { autônoma e historicamente garantida }\end{array}$} & \multicolumn{2}{|c|}{$\begin{array}{l}\text { Reprodução dependente do } \\
\text { mercado }\end{array}$} \\
\hline Circulação & & $\begin{array}{c}\text { Produção } \\
\text { comercializada }\end{array}$ & & $\begin{array}{l}\text { Fatores de produção e } \\
\text { insumos comprados }\end{array}$ & $\begin{array}{l}\text { Produção } \\
\text { comercializada }\end{array}$ \\
\hline Produção & $\begin{array}{l}\text { Reproduçãoo } \\
\text { dos fatores } \\
\text { de produçãoo } \\
\text { e insumos }\end{array}$ & $\begin{array}{l}\text { Resultado da } \\
\text { produção }\end{array}$ & $\begin{array}{l}\text { Reprodução } \\
\text { dos fatores de } \\
\text { produção e } \\
\text { insumos }\end{array}$ & $\begin{array}{l}\text { Fatores de } \\
\text { produção e insumos } \\
\text { utilizados }\end{array}$ & Produção \\
\hline
\end{tabular}

Fonte: Adaptado de PLOEG (1992, p. 174), PLOEG (2006, p. 25) e PLOEG (2008, p. $62)$.

Observando a figura, verifica-se que a produção para o mercado passa a comandar todo o processo produtivo. Essa produção para o mercado, que para os camponeses era mais esporádica, com a venda de alguns excedentes, aumenta cada vez mais. Por outro lado, os fatores de produção também precisam ser adquiridos fora da propriedade. A expressão mais clara disso são as novas tecnologias que vem em forma de "pacote" com o processo de modernização da agricultura. Fecha-se um círculo, onde a produção depende, crescentemente, da venda para o mercado, bem 
como, da compra dos fatores de produção, como sementes, adubo, pesticidas, máquinas, ferramentas. Para Ploeg:

\begin{abstract}
O resultado deste processo é uma divisão crescente do trabalho entre indústria e agricultura, assim como, entre diferentes unidades produtivas no interior do sistema agrícola. Porém, em contraste com a indústria, onde uma parte considerável da especialização crescente e da divisão do trabalho têm lugar no interior da fábrica (e portanto não implica um aumento importante na troca mercantil), o desenvolvimento agrícola implica um processo de externalização que gera uma multiplicação das relações mercantis. As tarefas que foram organizadas e coordenadas inicialmente, sob o mando do próprio agricultor, hão de ser coordenadas agora mediante o intercâmbio mercantil e por meio do sistema recém estabelecido das relações técnicoadministrativas. Esta externalização crescente, não somente afeta as atividades de produção, mas resulta também numa transformação completa do processo de reprodução (Ploeg, 1992, p. 169-70). Tradução livre. Grifos nossos.
\end{abstract}

Recentemente o autor avançou na análise das diferentes formas e graus de mercantilização da agricultura familiar. Segundo Ploeg (2006), as diferenças básicas entre os modos de produção residem nas diferentes inter-relações entre agricultura e mercado e no ordenamento associado ao processo de produção agrícola (figura 02).

Figura 02 - Diferentes formas de produção mercantil.

\begin{tabular}{|c|c|c|c|c|}
\hline $\begin{array}{c}\text { FORMA DE } \\
\text { PRODUÇÃO DE } \\
\text { MERCADORIA }\end{array}$ & $\begin{array}{c}\text { DOMÉSTICA } \\
(\mathrm{PD})\end{array}$ & $\begin{array}{c}\text { PEQUENA } \\
(\mathrm{PPM})\end{array}$ & $\begin{array}{c}\text { SIMPLES } \\
\text { (PSM) }\end{array}$ & $\begin{array}{c}\text { CAPITALISTA } \\
\text { (PCM) }\end{array}$ \\
\hline $\begin{array}{c}\text { Resultado da } \\
\text { produção }\end{array}$ & não-mercadoria & mercadoria & mercadoria & mercadoria \\
\hline Outros insumos & não-mercadoria & não-mercadoria & mercadoria & mercadoria \\
\hline Força de trabalho & não-mercadoria & não-mercadoria & não-mercadoria & mercadoria \\
\hline Objetivos & $\begin{array}{c}\text { auto- } \\
\text { abastecimento }\end{array}$ & sobrevivência & renda & mais-valia \\
\hline
\end{tabular}

Fonte: Adaptado de Ploeg (2006, p. 18).

Na Figura 02, as colunas PD (Produção Doméstica), PPM (Pequena Produção de Mercadorias) e PSM (Produção Simples de Mercadorias), demonstram os diferentes graus de mercantilização da agricultura familiar, com diferentes graus de interação com o mercado (compra de insumos ou destino da produção) e diferentes objetivos (auto-abastecimento, sobrevivência ou renda). No entanto, o que é comum para todas elas é a força de trabalho familiar (que entra no processo de produção não como uma mercadoria), e é esse aspecto que a distingue radicalmente da Produção Capitalista de Mercadorias (PCM), para a qual o resultado da produção, os insumos e a força de trabalho são mercadorias e o objetivo da sua produção é a extração da mais-valia. O que Abramovay (1992) chama de agricultura familiar altamente integrada ao mercado é o que Ploeg (2006) chamou de Produção Simples de Mercadorias, que obtém recursos do mercado, produz para o mercado com a finalidade de gerar renda, porém, a base da força de trabalho é familiar. É justamente essa interpretação, também feito por Friedmann (1978) que ajuda a entender a permanência da agricultura familiar no interior do capitalismo. Essa integração da agricultura familiar com os mercados (seja de forma direta, com intermediários, através de cooperativas, via integração com agroindústrias, etc.) foi ampliada com o processo de modernização da agricultura, o que culmina com um aprofundamento do 
processo de mercantilização, que se manifesta concretamente através das relações que os agricultores familiares estabelecem com o mercado, como por exemplo, através da comercialização da sua produção, aquisição de insumos e bens de consumo e acesso ao crédito.

Wanderley (2009), analisando o processo de modernização da agricultura brasileira e de modernização do meio rural faz uma análise das conseqüências para a agricultura familiar. Destaca que não ocorreu a decomposição anunciada do campesinato e que a agricultura familiar, enquanto forma social de produção "ocupa um lugar importante no cenário atual da economia e da sociedade brasileiras" (Wanderley, 2009, p. 185). Entretanto, lança como hipótese que, "mais do que, propriamente uma passagem irreversível e absoluta da condição de camponês tradicional para a de agricultor familiar "moderno", teríamos que considerar, simultaneamente, pontos de ruptura e elementos de continuidade entre as duas categorias sociais". Portanto, seria importante "considerar a capacidade de resistência e de adaptação dos agricultores aos novos contextos econômicos e sociais" (p. 189).

\footnotetext{
Mesmo integrada ao mercado e respondendo às suas exigências, o fato de permanecer familiar não é anódino, e tem como conseqüência o reconhecimento de que a lógica familiar, cuja origem está na tradição camponesa, não é abolida; ao contrário, ela permanece inspirando e orientando (...) as novas decisões que o agricultor deve tomar nos novos contextos a que está submetido (...) a família continua sendo o objetivo principal que define as estratégias de produção e de reprodução e a instância imediata de decisão (Wanderley, 2009, p. 189-190).
}

Assim, entre o que muda e o que permanece, Wanderley (2009) faz alguns destaques: a) é falsa a suposição que os camponeses não estaria interessados em produzir além de suas necessidades, pois ficou provado que os agricultores familiares "podem demonstrar uma importante capacidade de investimento, tanto maior quanto são efetivamente integrados aos mercados modernos" (p. 291-192); b) mudança no princípio do rendimento indivisível, pois "ao se integrar ao mercado, nas condições modernas de produção, a unidade familiar introduz, em seu funcionamento, a necessidade de pagamentos diferenciados" (p. 192); c) em relação ao tempo, "enquanto o camponês tradicional enfatizava o "passado e suas tradições", a agricultura moderna, ao introduzir a noção de progresso, transfere o primado ao futuro" (p. 192); d) a pluriatividade das famílias agrícolas, entendida como "uma estratégia da família, afim de, diversificando suas atividades, fora do estabelecimento, assegurar a reprodução deste e sua permanência como ponto de referência central e de convergência para todos os membros da família” (p. 193).

Qual o aprendizado? a) no Brasil a agricultura familiar é relevante do ponto de vista econômico e social; b) em função do processo de modernização da agricultura, que via de regra significa a ampliação das relações capitalistas na agricultura, esses agricultores se "metamorfosearam" através da "mercantilização"; c) permaneceu o trabalho familiar, porém, sua reprodução social passa a ser influenciada pela sua relação (cada vez maior), com os mercados; d) portanto, um novo desafio passa a ser compreender a "morfologia" dos mercados da agricultura familiar, o que poderá servir de inspiração para novas pesquisas sobre a temática. 


\section{Para não concluir}

Sempre me senti desconfortável com a expressão "conclusão", seja numa monografia, artigo, dissertação ou tese. Ela é muito pretensiosa. Considero mais adequado, e prefiro utilizar, "considerações finais". A expressão "para não concluir" não é original, encontrei no texto de Ploeg (2006) e pareceu-me bastante adequada, instigante e porque não dizer, dialética. O conhecimento, ou melhor, a busca pelo conhecimento representa uma caminhada e o conhecimento científico não é final, seja nas ciências sociais ou exatas. Como afirmava Lefebvre (1995, p. 241), "não esquecer que o processo de aprofundamento do conhecimento é infinito". Para quem utiliza o método dialético numa pesquisa, parece até contraditório utilizar a expressão "conclusão". Como enfatiza Lefebvre (1995, p. 241), "em certas fases do próprio pensamento, este deverá se transformar, se superar: modificar ou rejeitar sua forma, remanejar seu conteúdo".

Portanto, numa perspectiva dialética e pensando na ideia de "não concluir", vamos retomar alguns elementos discutidos no decorrer do texto para pensar o processo de mercantilização da agricultura familiar: a) pensar a reprodução social da agricultura familiar a partir das suas condições materiais e estar atento às particularidades históricas; b) a agricultura familiar não é "avessa" ao capitalismo e sua reprodução social possui ligação com os obstáculos naturais e a mão de obra familiar (produção simples de mercadorias); c) não considerar apenas o ambiente macro-estrutural, mas também, os indivíduos / famílias, que possuem motivações e estratégias de resistência; d) considerar que no Brasil, a relação com o mercado faz parte da história da agricultura familiar, não é algo posterior; f) quanto mais a agricultura se mercantiliza, amplia sua dependência dessa relação; g) existem diferentes graus de mercantilização, mas permanece a lógica do trabalho familiar; $\mathrm{h}$ ) uma análise da estrutura e dinâmica dos mercados da agricultura familiar parece ser uma possibilidade interessante de pesquisa para compreender sua reprodução social no capitalismo.

\section{Referências}

ABRAMOVAY, Ricardo. Paradigmas do capitalismo agrário em questão. São Paulo / Rio deJ aneiro / Campinas: Hucitec / Anpocs / Unicamp, 1992.

. Uma nova extensão rural para a agricultura familiar. In: SEMINÁRIO NĀCIŌNAL DE ASSISTÊNCIA TÉCNICA E EXTENSÃO RURAL. Brasília, DF. Anais..., 1997.

BRASIL. Ministério do Desenvolvimento Agrário. Agricultura familiar no Brasil e o censo agropecuário 2006. Brasília: MDA, 2009.

CHAYANOV, Alexander V. La organización de la unidad económica campesina. Buenos Aires: Nueva Visión, 1974.

ELLIS, Frank. Peasants Economics - Farm Households and Agrarian Development. Cambridge University: Cambridge, 1988. 
FAO/INCRA. Perfil da agricultura familiar no Brasil: dossiê estatístico. Brasília: Projeto UTF/ BRA/ 036/BRA, 1996.

FERNANDES, Rubem César (org.). Dilemas do socialismo: a controvérsia entre Marx, Engels e os Populistas Russos. Rio de J aneiro: Paz e Terra, 1982.

FRIEDMANN, Harriet. Simple commotity production and wage labour in the american plains. J ournal of Peasant Studies. London, v. 6, n. 1, p. 71-100, 1978.

GARCIA J ÚNIOR, Afrânio. O sul: caminho do roçado (estratégias de reprodução camponesa e transformação social). São Paulo. Ed. Marco Zero / Unb, 1989.

GERMER, Claus. A irrelevância prática da agricultura "familiar" para o emprego agrícola. In: Anais do Workshop Teórico da Economia Política da Agricultura. Campinas, UNICAMP, Instituto de Economia, 09 e 10 de dezembro de 1996. p. 331-366.

GOODMAN, David; SORJ, Bernardo; WILKINSON, John. Da lavoura às biotecnologias: agricultura e indústria no sistema internacional. Rio de Janeiro: Campus, 1990.

GRAZIANO DA SILVA, J osé. A modernização dolorosa: estrutura agrária, fronteira agrícola e trabalhadores rurais no Brasil. Rio de J aneiro: Zahar, 1982. ŪFRGS, 1999.

Tecnologia e agricultura familiar. Porto Alegre: Ed Universidade /

HEREDIA, B. A morada da vida: trabalho familiar de pequenos produtores do Nordeste do Brasil. Rio deJ aneiro: Paz e Terra, 1979.

HOBSBAWM, Eric. Era dos extremos: o breve século XX: 1914-1991. São Paulo: Companhia das Letras, 1995.

IBGE. Instituto Brasileiro de Geografia e Estatística. Censo agropecuário 2006: agricultura familiar - primeiros resultados - Brasil, grandes regiões e unidades da federação. Rio de J aneiro: IBGE, 2009.

JEAN, Bruno. A forma social da agricultura familiar contemporânea: sobrevivência ou criação da economia moderna. Cadernos de Sociologia. Porto Alegre, v. 6, 1994. pp. 51-75.

LAMARCHE, Huges (coord.). A agricultura familiar: comparação internacional: uma realidade multiforme. v. 1. Campinas: Ed. da UNICAMP, 1993.

A agricultura familiar: comparação internacional: do mito à realidade. v. 2. Campinas: Ed. da UNICAMP, 1999.

LEFEBVRE, Henri. Lógica formal lógica dialética. Rio de J aneiro: Civilização Brasileira, 1995. 
LÊNIN, Vladimir Ilich. O desenvolvimento do capitalismo na Rússia: o processo de formação do mercado interno para a grande indústria. 2. ed. São Paulo: Nova Cultural, 1985.

KAUTSKY, Karl. A questão agrária. São Paulo: Nova Cultural, 1986.

MANN, Suzan A.; DICKINSON, James M. Obstáculos ao desenvolvimento da agricultura capitalista. Literatura Econômica. São Paulo, v. 9, n. 1, p. 7-26, 1987.

MENDRAS, Henri. Sociedades camponesas. Rio de Janeiro: Zahar Editores, 1978.

MITRANY, David. Marx contra os camponeses. Rio de J aneiro: Ipanema, 1957.

MOREIRA, Roberto José. Agricultura familiar: processos sociais e competitividade. Rio deJ aneiro / Seropédica: Mauad / CPDA, 1999.

OLIVEIRA, Francisco de. A economia brasileira: crítica à razão dualista. 6. ed. Petrópolis: Vozes, 1988.

PLEIN, Clério. As metamorfoses da agricultura familiar: o caso do município de Iporã d' Oeste, Santa Catarina. Porto Alegre; UFRGS/ PGDR, 2003. [dissertação de mestrado].

PLEIN, Clério; SCHNEIDER, Sergio. Agricultura familiar e mercantilização. In: CASTILHO, Mara Lucy; RAMOS, José Maria (editores). Agronegócio e desenvolvimento sustentável. Francisco Beltrão: Calgan, 2003.

PLOEG, Jan Douwe Van Der. El processo de trabajo agricola y la mercantilizacion. In: GUZMAN, Eduardo Sevilla. Ecologia, campesinato y historia. Las Ediciones de la Piqueta, 1992. p. 135-195.

. O modo de produção camponês revisitado. In: SCHNEIDER, Sergio (org.) A diversidade da agricultura familiar. Porto Alegre: Editora da UFRGS, 2006. p. 13-54.

Camponeses e impérios alimentares: lutas por autonomia e sustentabilidade na era da globalização. Porto Alegre: UFRGS, 2008.

POLANYI, Karl. El mercado em la teoría y la historia. In: POLANYI, Karl, ARENSBERG, Conrad M. e PEARSON, Harry W. (org.). Comercio y mercado en los imperios antiguos. Barcelona: Labor, 1976, pp. 405-420.

PORTO, Maria Stela Grossi; SIQUEIRA, Deis Elucy. A pequena produção no Brasil: entre os conceitos teóricos e as categorias empíricas. Cadernos de Sociologia. Porto Alegre, v. 6, 1994. p.76-88

PROJETO DE COOPERAÇÃO TÉCNICA INCRA / FAO. Novo retrato da agricultura familiar: o Brasil redescoberto. Brasília, 2000. Disponível em http:/ www.INCRA.gov.br/ fao/ . Acesso em 04/ 06/ 2009. 
SERVOLIN, Claude. L'absostion de l'agriculture dans le mode de production capitaliste. In: TAVERNIER, Y.; GERVAIS, M.; SERVOLIN, C. L'univers politique dês paysans dans la France contemporaine. Paris: Presses de la Foundation National dês Scilences Politiques, 1972. p. 41-77.

SCHNEIDER, Sergio. Agricultura familiar e pluriatividade. Porto Alegre: PPGS/ UFRGS, 1999. [Tese de doutorado].

A pluriatividade na agricultura familiar. Porto Alegre: Editora da ÜFRGS, 2003.

VEIGA, J osé Eli da. O desenvolvimento agrícola: uma visão histórica. São Paulo: Hucitec, 1991.

WANDERLEY, Maria de Nazareth Baudel. O mundo rural como um espaço de vida: reflexões sobre a propriedade da terra, agricultura familiar e ruralidade. Porto Alegre: UFRGS, 2009.

WEBER, Max. Capitalismo e sociedade rural na Alemanha. In:

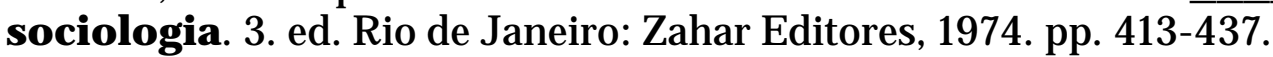
Ensaios de 